\title{
The Role of Cognitive and Cultural Sophistication on Diversity Outcomes: Differences Across Fields of Study
}

\author{
Brian P. An \\ Department of Educational Policy and Leadership Studies, University of Iowa \\ Wei-Lin Chen \\ Department of Educational Policy and Leadership Studies, University of Iowa
}

Received: September 22, 2014 Accepted: October 15, 2014 Published: October 18, 2014

doi:10.5296/jsss.v2i1.6338 URL: http://dx.doi.org/10.5296/jsss.v2i1.6338

\begin{abstract}
Social scientists generally consider college education important in increasing tolerance toward other social groups, and studies show a positive relation between education and tolerance. Despite this positive relation, previous research generally does not examine the influence of fields of study on diversity outcomes. Moreover, prior research has used crude measures to test the influence of cognitive and cultural sophistication, the proposed mechanism through which education increases tolerance. Using longitudinal data of college students, this research addressed whether the "liberalizing" effects of college education on diversity outcomes are due to the increase in cognitive and cultural sophistication, as proponents claim or whether these liberalizing effects of college education on diversity outcomes differ by fields of study. Partial support was found that cognitive and cultural sophistication increase diversity outcomes. Students' need for cognition and peer discussions about diversity increases diversity outcomes. Little evidence was found that the influence of cognitive and cultural sophistication on diversity outcomes differs by fields of study. Although the influence of cognitive and cultural sophistication on diversity outcomes is similar across fields of study, differences in the degree of exposure to cognitive and cultural sophistication account for a large share of the gap in diversity outcomes by fields of study.
\end{abstract}

Keywords: Cognitive sophistication, Diversity outcomes, Social tolerance, Fields of study 


\section{Introduction}

Social scientists remain interested in the democratic function of a college due to major demographic shifts in a nation's racial/ethnic composition. Using the United States context as an example, researchers note a decrease in the share of White Americans over time. The number of White students attending U.S. primary and secondary schools decreased slightly, from 31.5 million in 1993 to 30.5 million in 2005. Despite this relatively stable trend, the Whites' share of the U.S. student population dropped by 13\% (An \& Gamoran, 2009).

The decrease in the Whites' composition of the student population is mainly due to the increase of Hispanics attending U.S. schools. In 1972, Hispanic students comprised 6\% of all public students enrolled in elementary and secondary schools. In 2007, Hispanic students increased their population to $21 \%$ of all public students, making them the majority non-White population (National Center for Education Statistics [NCES], 2009).

These changes in the U.S. population suggest issues of social tolerance and diversity remain important. Social scientists note a renewal of support for immigration and restriction where supporters argue that immigrants threaten the nation's economy and security (Ayers, Hofstetter, Schnakenberg, \& Kolody, 2009). However, highly-educated individuals tend to oppose immigration restriction than less-educated individuals (Scheepers, Gijsberts, \& Coenders, 2002). As the population increasingly becomes racially/ethnically heterogeneous, several educators and researchers turn to the liberalizing influence of education on social tolerance.

Education, especially college education, is an important mechanism to increase individuals' social tolerance. Studies generally show a positive relation between education and tolerance whereby highly educated individuals are more likely to exhibit favorable attitudes toward other racial/ethnic groups than less-educated individuals (Heerwig \& McCabe, 2009; Nunn, Crockett, \& Williams, 1978; Sniderman \& Piazza, 1993). The consistency of this finding has led some writers to consider it "among the most replicated findings in the social sciences" (Gaasholt \& Togeby, 1995, p. 267).

Social scientists often argue that cognitive and cultural sophistication mediates the relation between college education and social tolerance. Individuals attending college are more likely to acquire knowledge, to have greater exposure to multiple views and values, and are more likely to improve their critical-thinking skills than those who did not attend college (Bobo \& Licari, 1989; Nunn et al., 1978; Whitt, Edison, Pascarella, Terenzini, \& Nora, 2001). Individuals also tend to gain knowledge of civil liberties as they receive more schooling. A college environment, therefore, allows individuals to develop and expand their commitments to democratic principles (Nunn et al., 1978; Sniderman \& Piazza, 1993).

Despite the extant literature examining the link between cognitive and cultural sophistication and social tolerance, previous research is limited in three ways. First, few researchers consider the interplay between fields of study in college and social tolerance (Guimond \& Palmer, 1996; Sidanius, Pratto, Martin, \& Stallworth, 1991). Researchers often assume that a college education in general exerts a liberalizing effect on social tolerance (e.g., Heerwig \& McCabe, 2009; Treas, 2002), and researchers underplay students' experience in their fields of study as influencing their levels of social tolerance. Second, researchers often overlook 
whether college attendance increases social tolerance because of an increase in cognitive and cultural sophistication (Bobo \& Licari, 1989). Third, when testing the role of cognitive and cultural sophistication on the relation between education and social tolerance, researchers have used crude measures such as verbal ability or educational attainment to capture cognitive and cultural sophistication (Bobo \& Licari, 1989; Geys \& Heyndels, 2003; Krosnick \& Alwin, 1987). These studies do not indicate which aspects of cognitive and cultural sophistication drive their results.

Using longitudinal data of college students, the influence of cognitive and cultural sophistication on diversity outcomes is tested. Unlike previous studies, several measures of cognitive and cultural sophistication are included. Moreover, the study tested whether students pursuing a degree in "professional" fields such as fields designed to train individuals with skills required for entry into specific occupations experience lower liberalizing effects than those pursuing "traditional" fields, such as arts and science (Goyette \& Mullen, 2006; Seifert et al., 2008).

This study focused on the relation between education and tolerance. The study directly examined the mechanism, cognitive and cultural sophistication, which researchers purport as the means through which college experiences instill democratic principles. Moreover, few researchers consider how a student's field of study influences the relation between cognitive and cultural sophistication, and diversity outcomes. Differences in diversity outcomes may be due to differences in the level of cognitive and cultural sophistication, which we argue is attributed partly to students' field of study. In addition, the effects of cognitive and cultural sophistication may differ across fields of study. The study addressed two research questions: 1) Do the differences in diversity outcomes by fields of study due to differences in the students' exposure to cognitive and cultural sophistication?, and 2) Does the liberalizing effect of education on diversity outcomes vary across fields of study?

The following section discusses the role of education on social tolerance such as the increase of educational attainment across generations and the importance of this shift on educational attainment in relation to social tolerance. The study determined how college participation alters a person's attitudes toward others. Second, it also determined how students' college experience, through their college major choice, serve as a mechanism that alters the liberalizing effect of education on social tolerance. Third, the study also determined the limitations of previous research on the influence of education on attitudes toward others and how our study addresses these limitations.

\section{Literature Review}

\subsection{Cohort Succession and the Role of Education on Tolerance}

Social scientists note that U.S. citizens have become increasingly more tolerant over time. For example, since 1940, White Americans have held increasingly favorable attitudes toward African Americans. These attitudes denounce biological assertions as causes of social positions. In fact, Whites are in support of general principles that bring about racial equality (Bobo \& Kluegel, 1993). In 1942, 68\% of White adults favored keeping schools separate for White and Black children. In 1995, only 4\% of White adults favored segregating schools (Schuman, Steeh, Bobo, \& Krysan, 1997). 
Part of the explanation for this change in individuals' attitude toward others is, societies become more tolerant as the younger generation replaces the older generation (Stouffer, 1955; Wilson, 1994). Although older adults are able to alter their attitudes brought by social change, younger adults are more receptive to these changes. Younger adults are more likely to participate in social movements and they are more likely to do so prior to events that constrain their lives, such as family or occupation (Treas, 2002). A notable portion of the cohort-succession effect is due to the newer cohort attaining more education and replacing the older cohort (Wilson, 1994).

\subsection{How College Attendance Increases Individuals' Positive Attitudes Toward Others}

Social scientists often consider college education the central mechanism through which individuals increase their tolerance toward other social groups. When students attend college, they are exposed to different values, viewpoints, and cultures. As students increasingly participate in diversity-related activities (e.g., cultural workshops and interracial interactions), they tend to gain greater tolerance to individual differences than those who do not participate in these activities (Chang, Denson, Saenz, \& Misa, 2006; Whitt et al., 2001).

Furthermore, college participation leads to "moral enlightenment" where a college setting provides individuals with an opportunity to raise their cognitive and cultural sophistication (Bobo \& Licari, 1989; Nunn et al., 1978). In college, individuals have greater exposure to others whose viewpoints differ from their own and they thereby better understand cultural norms and values (Sniderman \& Piazza, 1993). College-educated individuals tend to reject undemocratic prejudices, and as a result, show greater tolerance toward others - even among those who they dislike - than less-educated individuals (Bobo \& Licari, 1989; Gaasholt \& Togeby, 1995; Nunn et al., 1978). Research further indicates that cognitive and cultural sophistication account for about one-third of the relation between education and social tolerance (Bobo \& Licari, 1989).

Sniderman and Piazza (1993) find college-educated Whites tend to have a better understanding of core principles of their political ideology than those without a college degree. Compared to college-educated conservatives, college-educated liberals are more likely to support government guarantees of equal opportunity. Importantly, this support (or opposition) among college-educated Whites is unswayed by the target group (e.g., women or African Americans). By contrast, less-educated Whites, regardless of ideology, are more likely to support policies for women than for African Americans. This double standard is partly due to less-educated Whites' lack of understanding of what it means to be a liberal or conservative and they, therefore, base their attitudes on other criteria (Sniderman \& Piazza, 1993).

An educated population often benefits society in that college-educated elites participate in cultural innovations which often diffuse to less-educated individuals (Treas, 2002). Moore and Ovadia (2006) suggest that individuals in concentrated areas of college-educated adults share macro-individual norms and policies, proposed and possibly enforced by the college-educated majority, that adhere to favorable attitudes toward others (e.g., anti-discrimination laws). 


\subsection{Fields of Study and the Liberalizing Effect of Education}

Although previous research showed how colleges can serve as an avenue to raise a student's cognitive and cultural sophistication, the rise of professional education potentially threatens, or at least lessens, this influence. Advocates of professional education consider the college and university as a training facility for a skilled workforce. As such, professional education emphasizes more on practical and specialized knowledge and less on general knowledge and intellectual inquiry - as advocates of liberal arts education contend (Goyette \& Mullen, 2006; Seifert et al., 2008).

Traditional fields of study, such as math, science, social science, and humanities, increase reasoning skills - an indicator of cognitive sophistication-greater than professional fields, such as education, human services, and business (Arum, Roksa, \& Velez, 2008). Although students' social tolerance toward others become more egalitarian the longer they are in college, in general, social science majors, in particular, are more likely to display egalitarian attitudes than business majors (Guimond \& Palmer, 1996; Sidanius et al., 1991).

Part of the rise in professional majors is its strong link between content knowledge and labor-market outcomes (Freeman \& Hirsch, 2008; Robst, 2007). A notable portion of differences in earnings, as much as $35 \%$, is attributable to differences in college major (Grogger \& Eide, 1995). Since 1960s, students have shifted away from liberal arts degrees to professional degrees. Recently, over $60 \%$ of individuals graduated with a professional degree, which is approximately 15 percentage points higher than in 1960 (Brint, Riddle, Turk-Bicakci, \& Levy, 2005).

Certainly, universities should not cease a professional/occupational mission. Many individuals, especially those from less-privileged backgrounds, often seek a professional degree as a means for social advancement (Goyette \& Mullen, 2006). Rather, advocates of a liberal arts education contend that students' college experience, through their choice of major, should elicit an education that maintains various returns to a college degree. During junior and senior years of college, students take the majority of courses in their respective major. Therefore, college majors provide an opportunity to socialize students to not only collegiate norms but also to societal norms (Seifert, 2007).

\subsection{The Study's Contributions to Literature}

Our study contributes to previous research in several ways. First, this study considered whether fields of study influence the relation between cognitive and cultural sophistication, and social tolerance, while researchers often examine whether college-degree attainment or college duration influence individuals' attitude toward others (Heerwig \& McCabe, 2009; Park, 2009; Treas, 2002). Previous studies rarely consider whether differences in fields of study-where college students take the majority of their courses after their sophomore year-influence their gains in cognitive and cultural sophistication.

Second, researchers spend less time considering whether college attendance increases social tolerance because of an increase in cognitive and cultural sophistication. Instead, researchers typically concentrate on school activities related to diversity. Few people would argue against these diversity activities as important in raising an individual's diversity awareness. However, the present study considered that the main feature of education, as a means to increase social 
tolerance, is that, individuals who attend college raise their cognitive and cultural sophistication. These developments transcend across specific social settings and allow individuals to assess critically broad social issues.

Third, previous research examining the influence of cognitive and cultural sophistication on social tolerance has used crude measures, such as educational attainment or verbal ability, to proxy for cognitive and cultural sophistication (Bobo \& Licari, 1989; Geys \& Heyndels, 2003; Krosnick \& Alwin, 1987). Although those attaining a college degree tend to have higher levels of cognitive and cultural sophistication than those not attaining a college degree, other factors may affect both college-degree attainment and social tolerance. The present study focused on the extent to which cognitive and cultural sophistication drive the positive relation between education and social tolerance.

\section{Data and Procedures}

The 2006 cohort of the Wabash National Study of Liberal Arts Education (WNSLAE) was used. The WNSLAE is a longitudinal study of first-time college students from 17 U.S. postsecondary schools. These students were resurveyed in spring of their first year (time 2) in college and again in spring of their fourth year (time 3).

There are several advantages of WNSLAE over other surveys. First, the WNSLAE comprises of a recent college student cohort. This study therefore provided updated results to studies that examined the relation between cognitive and cultural sophistication, and diversity outcomes but made use of older cohorts. Second, the WNSLAE covers a four-year span, which allowed the researchers to investigate the influence of cognitive and cultural sophistication over a full or near full dose of college participation. Third, investigators asked students to respond multiple times to several indicators over the course of the study. As a result, the study had pre-post outcome indicators and therefore did not have to rely on self-reported gain scores. Fourth, the WNSLAE contains a rich array of indicators capturing cognitive and cultural sophistication, and diversity outcomes.

The sample had 2,212 students who responded to both fall 2006 (time 1) and spring 2010 (time 3) follow-up collection. However, investigators randomly assigned half of the students to a critical-thinking assessment and the other half to a moral-reasoning assessment. The study used the critical-thinking assessment, which gave us a sample of 1,075 students. One hundred sixty students (15\%) with "other" or missing majors were dropped, resulting in a final sample of 914 students. Cluster sampling and Stata 12.1 were used to conduct analyses.

Multiple imputation techniques were used to handle missing information. Listwise deletion would lead to a sample loss of $22 \%$. Ten replications of the data set were created, and imputed values of the dependent variable were removed because these imputed values add little, and may even add noise, to the estimates (von Hippel, 2007). 
Table 1. Description of variables

\begin{tabular}{|c|c|c|c|}
\hline Variables & Description & \multicolumn{2}{|c|}{ Mean S.D } \\
\hline \multicolumn{4}{|l|}{ Dependent variable } \\
\hline $\begin{array}{l}\text { Orientation toward } \\
\text { diversity }\end{array}$ & $\begin{array}{l}\text { Miville-Guzman Universality-Diversity ( } 15 \text { items; } \\
\text { alpha }=0.80 \text { ) measures students' universal diverse } \\
\text { orientation ( } 1=\text { Strongly disagree; } 5=\text { Strongly agree) }\end{array}$ & 4.7 & 0.6 \\
\hline Reflection of views & $\begin{array}{l}\text { Extent a student tried to understand better someone } \\
\text { else's views and the extent a student examined } \\
\text { strengths and weaknesses of own views (standardized; } \\
\text { 2-items; alpha }=0.76 \text { ) }\end{array}$ & 0.0 & 0.9 \\
\hline Diversity experiences & $\begin{array}{l}\text { Extent a student values diversity experiences in } \\
\text { education (standardized; } 5 \text {-items; alpha } 0.82 \text { ) }\end{array}$ & 0.0 & 0.8 \\
\hline
\end{tabular}

Cognitive sophistication

Collegiate Assessment of Academic Proficiency

Critical thinking

(CAAP; alpha=0.82) measures a student's ability to

clarify, analyze, evaluate, and extend arguments

$66.4 \quad 4.8$

(scores from 49 to 73 )

A student's tendency to engage in cognitive activities

Need for cognition (18-items; alpha $=0.89)(1=$ Strongly disagree;

$5=$ Strongly agree)

Cognitively intense

Exams or assignments that require displays of

activities

critical-thinking skills in which students participate $\quad \begin{array}{lll}0.0 & 0.8\end{array}$

(standardized; 4-items; alpha $=0.83$ )

Cognitively intense engagement with faculty

Faculty-student interactions in which students display articulation of arguments and higher-order thinking $\quad \begin{array}{lll}0.0 & 0.7\end{array}$ (standardized; 5-items; alpha 0.78).

Extent a student had serious discussions regarding diversity issues, as well as the extent a student had

Peer discussions about serious conversations with those who are of different $\quad \begin{array}{lll}0.0 & 0.8\end{array}$ diversity racial/ethnic backgrounds (standardized; 7-items; alpha 0.88)

Background

\begin{tabular}{llrl}
\hline Female & Student is female & 0.6 & 0.5 \\
\hline Underrepresented minority & Student is an underrepresented minority & 0.1 & 0.3 \\
\hline Parent education (B.A.) & At least one parent earned a bachelor's degree & 0.3 & 0.5 \\
\hline $\begin{array}{l}\text { Parent education (Post-B.A.) } \\
\text { at least one parent earned a post-bachelor's or } \\
\text { advanced degree }\end{array}$ & 0.4 & 0.5
\end{tabular}


Racial composition in high Whether high school racial composition was more school than $50 \%$ minority

Academic achievement

\begin{tabular}{llcc}
\hline SAT scores & SAT score (100 points) & 12.4 & 1.6 \\
\hline $\begin{array}{l}\text { Aspirations toward liberal } \\
\text { arts majors }\end{array}$ & Aspirations toward liberal arts majors & 0.4 & 0.5 \\
\hline $\begin{array}{l}\text { Aspirations toward other } \\
\text { majors/undecided }\end{array}$ & $\begin{array}{l}\text { Aspirations toward other majors/undecided } \\
\text { (professional majors are the omitted category) }\end{array}$ & 0.3 & 0.4 \\
\hline
\end{tabular}

Pre-college measures of endogenous variables

Pre-college critical thinking See explanation of endogenous variables

$64.1 \quad 5.2$

Pre-college need for cognition

See explanation of endogenous variables

Pre-college orientation toward diversity

See explanation of endogenous variables

Pre-college reflection of

Taken in spring semester of first year. See explanation views of endogenous variables

Pre-college values diversity experiences in education

See explanation of endogenous variables

Note: WNSLAE 2006. Sample size is 914 respondents.

\subsection{Diversity Outcomes}

Outcome measures contain indicators capturing students' openness to diversity and challenges to their social values and ideals (see Table 1 for a description of variables). Typically, social scientists define tolerance as a person's willingness to allow for objects or expression of ideas and interests, even when the person opposes the object or idea (Bobo \& Licari, 1989; Wilson, 1994). Unfortunately, the WNSLAE data set does not have direct measures of social tolerance. Instead, the WNSLAE data set has indicators capturing diversity outcomes, which serve as precursors to social tolerance (Taylor, 1998; Whitt et al., 2001). For example, investigators asked the respondents about the extent to which they tried to understand better someone else's views and the importance for them to influence social values, promote racial understanding, and to improve understanding of other countries and cultures. Students' openness to diversity, and challenges to their social values and ideals were used as markers toward social tolerance.

Nevertheless, the study avoided social tolerance, per se, and concentrate towards diversity outcomes. Although this conceptual alteration weakens the examination of social tolerance, social scientists focus more on whether education raises tolerance toward others and they pay less attention on how education raises tolerance. This study, therefore, provided insights on social tolerance and that cognitive and cultural sophistication was examined as a mechanism through which education leads to tolerance toward others. 
Three diversity outcomes and all outcomes were taken during students' fourth year in college (time 3). The first outcome is students' orientation toward diversity as measured by Miville-Guzman Universality-Diversity Scale (M-GUDS; 15 items; alpha =0.80). M-GUDS reflects how aware and accepting individuals are to similarities and differences among individuals (Pascarella \& Colleagues, 2007). Reflection of views ( 2 items; alpha $=0.76$ ) is the second diversity outcome. This outcome represents the extent in which students try to understand better someone else's views and the extent in which they examine strengths and weaknesses of their own views. The third diversity outcome is the extent students value diversity experiences in education ( 5 items; alpha $=0.82$ ), such as students' belief that learning about people from different cultures is an important part of their college education, and their enjoyment of having discussions with people whose ideas and values are different from their own.

\subsection{Cognitive and Cultural Sophistication Measures}

The study refined cognitive and cultural sophistication. Prior research has used educational attainment (Geys \& Heyndels, 2003; Krosnick \& Alwin, 1987) or verbal ability (Bobo \& Licari, 1989) proxies for cognitive and cultural sophistication. In addition to abstract conceptual thinking, researchers have identified exposure to varying viewpoints and a better understanding of values and norms of American culture as important for cognitive and cultural sophistication (Sniderman \& Piazza, 1993).

Five cognitive and cultural sophistication indicators were included in the analysis of the study, and all indicators were taken at time 3. The first indicator is critical-thinking skills, which was measured using the Collegiate Assessment of Academic Proficiency (CAAP; alpha = 0.82) Critical Thinking Test. ACT developed CAAP to measure students' ability to analyze, evaluate, and extend arguments (Pascarella \& Colleagues, 2007). CAAP is a 40-minute, 32 -item test that has four passages, and each passage contains arguments that use a variety of formats (e.g., case studies, debates, dialogues, statistical and empirical results, and editorials).

The second measure represents students' disposition or willingness to think critically and to apply their critical-thinking skills. Cacioppo, Petty, and Kao's need for cognition was used, an 18-item scale (alpha $=0.89$ ) that captures students' tendency to engage in cognitive activities (Center of Inquiry at Wabash College, 2011). The third measure of cognitive and cultural sophistication is the extent students engage in cognitively intense activities - exams or assignments that require students to display their critical-thinking skills (4 items; alpha = 0.83 ). Some examples of cognitively intense activities are exams or assignments that require students to argue for or against a particular point of view, and exams or assignments that require students to compare or contrast topics or ideas from a course. Cognitively intense engagement with faculty represents the fourth measure of cognitive and cultural sophistication ( 5 items; alpha $=0.78$ ). This measure captures faculty-student interactions in which students display articulation of arguments and higher-order thinking, such as the degree to which faculty ask students to argue for or against a particular point of view or ask challenging questions in class.

The final indicator is a measure of peer discussions about diversity ( 7 items; alpha $=0.88$ ). This measure captures the extent by which students had serious discussions as regards to diversity issues (e.g., lifestyles, customs, human rights, and social justice), as well as the 
extent by which students had serious conversations with those who are of different racial and ethnic backgrounds. This interaction is an important form of diversity exposure which offers opportunities for individuals to update their knowledge of out-group members (Gurin, Dey, Hurtado, \& Gurin, 2002).

\subsection{Fields of Study}

Liberal arts fields include arts and humanities, biological science, physical science, and social science. Professional fields include business, education, engineering, and other professional fields.

\subsection{Pre-College Measures}

Several pre-college indicators are included to control variables that possibly confound the relation between cognitive and cultural sophistication, and diversity. Race is a binary indicator of a student who is an underrepresented minority. A student's gender was coded as 1 for female. Parental education is a series of binary indicators where a student has at least one parent who attained a bachelor's degree or has at least one parent who attained a post-bachelor's degree (the omitted group is parents who did not attain a bachelor's degree). Pre-college diversity captures whether a student's high school racial composition was more than 50\% minority. A student's SAT scores were included as 100-point increases.

Pre-college measures of critical thinking and need for cognition were also included. Pre-college measures of cognitively intense activities and cognitively intense engagement with faculty were not included because these activities and interactions occurred during a student's college experience. Moreover, pre-college measures of each outcome such as orientation toward diversity, reflection of views, and values diversity experiences in education were included. These pre-college cognitive and cultural sophistication, and outcome measures account for cumulative effects of family background, achievement, and experiences related to cognitive and cultural sophistication, and diversity outcomes prior to college entry (Hanushek, Kain, \& Rivkin, 2009).

\subsection{Statistical Methods}

Two analyses were employed to examine whether fields of study influence the relation between cognitive and cultural sophistication and diversity outcomes. In the first analysis, OLS models were estimated for each outcome and the sample was divided into two groups: liberal arts and professional fields. The estimated coefficient of a given variable was formally tested whether it differs across fields of study (Paternoster, Brame, Mazerolle, \& Piquero, 1998).

In the second analysis, the Blinder-Oaxaca decomposition was applied to analyze gaps in diversity outcomes by fields of study. The gap in diversity outcomes by fields of study can be expressed as simply the mean outcome gap (Jann, 2008)

$$
R=E\left(Y_{L}\right)-E\left(Y_{V}\right)
$$

where $E\left(Y_{L}\right)$ and $E\left(Y_{V}\right)$ represent the expected value of the diversity outcome for liberal arts majors and professional majors, respectively. The Blinder-Oaxaca approach expresses 


\section{Macrothink}

the expected value of the diversity outcome $E(Y)$ as two linear models, one model for each group,

$$
\begin{aligned}
& E\left(Y_{L}\right)=\beta_{L} X_{L}+\varepsilon_{L} \\
& E\left(Y_{V}\right)=\beta_{V} X_{V}+\varepsilon_{V}
\end{aligned}
$$

where $\beta_{L}$ and $\beta_{V}$ represent slope parameters, $X_{L}$ and $X_{V}$ denote a vector of predictors, and $\varepsilon_{L}$ and $\varepsilon_{V}$ represent the error term (Jann, 2008). The outcome gap is the difference in the predicted values of the dependent variable between liberal arts and professional majors with the regressors set at their group-specific means

$$
R=E\left(Y_{L}\right)-E\left(Y_{V}\right)=E\left(X_{L}\right) \beta_{L}-E\left(X_{V}\right) \beta_{V}
$$

The Blinder-Oaxaca approach decomposes mean differences in diversity outcomes between liberal arts majors and professional majors into two parts. The first part, the endowment effect (Jann, 2008),

$$
Q=\left[E\left(X_{L}\right)-E\left(X_{V}\right)\right] \beta^{*}
$$

is the portion of the outcome difference between liberal arts majors and professional majors that is due to group differences in the distribution of covariates (e.g., peer discussions about diversity, cognitively intense activities, and need for cognition). In other words, what would happen to the gap in a diversity outcome between liberal arts and professional majors if professional majors had characteristics of liberal arts majors?

The second part, the coefficient effect,

$$
U=E\left(X_{L}\right)\left(\beta_{L}-\beta^{*}\right)+E\left(X_{V}\right)\left(\beta^{*}-\beta_{V}\right)
$$

is the portion of the outcome difference between groups that is due to differential effects of covariates. To put differently, what would happen to the gap in a diversity outcome if professional majors had the effects of cognitive and cultural sophistication, for example, of liberal-arts majors? $\beta^{*}$ represents a vector of nondiscriminatory coefficients. However, $\beta^{*}$ is an unknown quantity and therefore requires identification. One solution which can be adopted is to use coefficients from a regression model of a pooled sample (Jann, 2008). 
Table 2. OLS models of diversity outcomes by fields of study

\begin{tabular}{|c|c|c|c|}
\hline Values diversity experiences & $\begin{array}{l}\text { Liberal arts } \\
\text { Coef S.E. }\end{array}$ & $\begin{array}{l}\text { Vocational } \\
\text { Coef S.E. }\end{array}$ & \\
\hline Critical thinking & $0.01(0.01)$ & $-0.01(0.01)$ & \\
\hline Need for cognition & $0.27(0.04)^{* * *}$ & $* 0.32(0.05)$ & $* * *$ \\
\hline Cognitively intense activities & $-0.03(0.05)$ & $0.05(0.04)$ & \\
\hline Cognitively intense engagement with faculty & $0.09(0.05) *$ & $0.12(0.05)$ & * \\
\hline Peer discussions about diversity & $0.39(0.04)^{* * *}$ & $* 0.36(0.04)$ & $* * *$ \\
\hline \multicolumn{4}{|l|}{ Control variables } \\
\hline Female & $0.13(0.05) *$ & $0.05(0.06)$ & \\
\hline Underrepresented minority & $-0.03(0.06)$ & $0.00(0.09)$ & \\
\hline Parent education (B.A.) & $0.03(0.06)$ & $0.01(0.06)$ & \\
\hline Parent education (Post-B.A.) & $0.09(0.05) \dagger$ & $0.00(0.07)$ & \\
\hline Racial composition in high school & $0.08(0.05)$ & $-0.14(0.06)$ & $*(\#)$ \\
\hline SAT scores & $-0.05(0.02) * *$ & $-0.01(0.04)$ & \\
\hline Aspirations toward liberal arts majors & $0.05(0.08)$ & $0.08(0.11)$ & \\
\hline Aspirations toward other majors/undecided & $0.05(0.08)$ & $-0.02(0.08)$ & \\
\hline Pre-college critical thinking & $0.01(0.01)$ & $0.00(0.01)$ & \\
\hline Pre-college need for cognition & $-0.19(0.06) * *$ & $-0.23(0.08)$ & $* *$ \\
\hline Pre-college values diversity experiences in education & $0.25(0.05)^{* * *}$ & $0.22(0.06)$ & $* * *$ \\
\hline Pre-college orientation toward diversity & $0.18(0.07) * *$ & $0.21(0.08)$ & $* *$ \\
\hline Pre-college reflection of views & $-0.03(0.03)$ & $-0.05(0.04)$ & \\
\hline \multirow[t]{2}{*}{ Constant } & $-1.75(0.44)^{* * *}$ & ${ }^{k}-0.47(0.60)$ & \\
\hline & Liberal arts & \multicolumn{2}{|c|}{ Vocational } \\
\hline Orientation toward diversity & Coef S.E. & Coef S.E. & \\
\hline Critical thinking & $0.01(0.01)$ & $0.01(0.01)$ & \\
\hline Need for cognition & $0.24(0.04) * * *$ & $0.27(0.03)$ & $* * *$ \\
\hline Cognitively intense activities & $-0.04(0.04)$ & $0.05(0.04)$ & \\
\hline Cognitively intense engagement with faculty & $0.05(0.03)$ & $-0.05(0.03)$ & $\dagger(\#)$ \\
\hline Peer discussions about diversity & $0.28(0.03)^{* * *}$ & $0.28(0.03)$ & $* * *$ \\
\hline \multicolumn{4}{|l|}{ Control variables } \\
\hline Female & $0.12(0.04) * *$ & $0.07(0.04)$ & $\dagger$ \\
\hline
\end{tabular}


Underrepresented minority

Parent education (B.A.)

Parent education (Post-B.A.)

Racial composition in high school

SAT scores

Aspirations toward liberal arts majors

Aspirations toward other majors/undecided

Pre-college critical thinking

Pre-college need for cognition

Pre-college values diversity experiences in education

Pre-college orientation toward diversity

Pre-college reflection of views

Constant

\section{Reflection of views}

Critical thinking

Need for cognition

Cognitively intense activities

Cognitively intense engagement with faculty

Peer discussions about diversity

Control Variables

Female

Underrepresented minority

Parent education (B.A.)

Parent education (Post-B.A.)

Racial composition in high school

SAT scores

Aspirations toward liberal arts majors

Aspirations toward other majors/undecided

Pre-college critical thinking

Pre-college need for cognition

\begin{tabular}{|c|c|c|}
\hline $0.02(0.08)$ & $-0.16(0.05)$ & $* * *$ \\
\hline $0.08(0.04) \dagger$ & $0.09(0.04)$ & $*$ \\
\hline $0.10(0.05) \dagger$ & $0.10(0.06)$ & $\dagger$ \\
\hline$-0.01(0.06)$ & $0.00(0.05)$ & \\
\hline$-0.01(0.01)$ & $-0.03(0.01)$ & $\dagger$ \\
\hline$-0.03(0.04)$ & $-0.06(0.08)$ & \\
\hline$-0.03(0.05)$ & $0.11(0.05)$ & $*$ \\
\hline $0.00(0.01)$ & $-0.01(0.01)$ & \\
\hline$-0.19(0.04)^{* * *}$ & $*-0.09(0.05)$ & $*$ \\
\hline $0.04(0.04)$ & $-0.05(0.03)$ & \\
\hline $0.39(0.07)^{* * *}$ & * $0.49(0.05)$ & $* * *$ \\
\hline $0.01(0.02)$ & $0.02(0.04)$ & \\
\hline $2.20(0.45)^{* * *}$ & * $2.11(0.46)$ & $* * *$ \\
\hline Liberal arts & Vocational & \\
\hline Coef S.E. & Coef S.E. & \\
\hline $0.01(0.01)$ & $0.02(0.01)$ & \\
\hline $0.32(0.06)^{* * *}$ & $* 0.14(0.08)$ & $\dagger$ \\
\hline $0.11(0.04) * *$ & $0.14(0.04)$ & $* * *$ \\
\hline $0.16(0.05) * *$ & $0.04(0.10)$ & \\
\hline $0.28(0.05)^{* * *}$ & $* 0.34(0.05)$ & $* * *$ \\
\hline $0.07(0.03) *$ & $0.01(0.06)$ & \\
\hline $0.04(0.07)$ & $-0.09(0.10)$ & \\
\hline $0.11(0.07)$ & $0.38(0.09)^{*}$ & ** (\#) \\
\hline $0.09(0.06)$ & $0.26(0.13)$ & $\dagger$ \\
\hline$-0.03(0.07)$ & $0.01(0.12)$ & \\
\hline$-0.04(0.02) \dagger$ & $-0.07(0.04)$ & $*$ \\
\hline$-0.03(0.08)$ & $-0.16(0.14)$ & \\
\hline$-0.14(0.08) \dagger$ & $0.01(0.08)$ & \\
\hline $0.00(0.01)$ & $0.00(0.01)$ & \\
\hline$-0.13(0.04) * *$ & $0.09(0.08)$ & $(\#)$ \\
\hline $0.04(0.07)$ & $0.01(0.07)$ & \\
\hline
\end{tabular}

Pre-college values diversity experiences in education 
Pre-college orientation toward diversity

$-0.02(0.06) \quad 0.03(0.06)$

Pre-college reflection of views

$$
0.26(0.04) * * * 0.25(0.05) * * *
$$

Constant

$-1.07(0.53) *-1.82(0.88)$

Note: WNSLAE 2006. Standard errors are in parenthesis and are adjusted for clustering. (\#) denotes a statistically significant difference in the estimated coefficient between liberal arts and professional fields. Sample size is 914 respondents. $\dagger \mathrm{p}<.10, * \mathrm{p}<.05, * * \mathrm{p}<.01, * * * \mathrm{p}$ $<.001$ (two-tailed).

\section{Results}

Table 2 shows results from the OLS regression where the influence of cognitive and cultural sophistication on diversity outcomes, which controls pre-college characteristics such as students' initial levels of diversity, were estimated. Not surprisingly, pre-college diversity measures are associated with diversity outcomes. There is also a relation between pre-college need for cognition and diversity outcomes, although surprisingly, the effect is negative. The positive effect of need for cognition at time 3 on diversity outcomes indicates that multicollinearity may drive the negative effect of pre-college need for cognition (see Supplemental Analyses section for further discussion of the relation between pre-college need for cognition and diversity outcomes).

Partial support was found that cognitive and cultural sophistication increase diversity outcomes. Consistent with expectations, students' need for cognition influences their value toward diversity experiences, orientation toward diversity, and reflection of views; although the relation between need for cognition and reflection of views is moderately significant for professional majors $(p<0.10)$. For example, a standard-deviation increase in need for cognition raises a student's orientation toward diversity by $0.24-0.27$ standard deviations. Furthermore, students' cognitively intense activities increase their reflection of views, where the influence for this outcome ranges from 0.11 to 0.14 standard deviations. There is a positive relation between students' cognitively intense engagement with faculty and their values toward diversity experiences, although this relation is modest (0.09-0.12 standard deviations). Surprisingly, there is little evidence that critical thinking raises diversity outcomes (see Supplemental Analyses section for further discussion). Students' peer discussions about diversity positively influence all three diversity outcomes. Moreover, peer discussions about diversity are among the strongest predictor of diversity outcomes in the model, with an influence between 0.28 and 0.39 standard deviations depending on the outcome.

With few exceptions, there is little difference across fields of study in the influence of cognitive and cultural sophistication on diversity outcomes. Cognitively intense engagement with faculty exerts a larger influence on orientation toward diversity for liberal arts majors than for professional majors.

In summary, there is evidence that cognitive and cultural sophistication increase diversity outcomes. Moreover, the influence of cognitive and cultural sophistication on diversity outcomes is similar across fields of study. Therefore, there is little support that professional 
education lowers the liberalizing effect of college. Although the influence of cognitive and cultural sophistication on diversity outcomes is similar across fields of study, for the most part, the degree of exposure to cognitive and cultural sophistication may lead to differences in diversity outcomes by fields of study.

Table 3. Blinder-Oaxaca decomposition of fields-of-study differences in diversity outcomes

\begin{tabular}{lllll}
\hline & \multicolumn{4}{c}{ Diversity outcomes } \\
& Value & Orient & Reflect \\
& $(\%$ explain $)$ & $(\%$ explain $)$ & $(\%$ explain $)$ & \\
\hline Difference & 0.29 & $* * *(0.22)$ & $* * * 0.31$ & $* * *$
\end{tabular}

\section{Endowment effects}

Total

$$
0.32(109.1 \%) * * * 0.25(115.3 \%) * * * 0.34(108.7 \%) * * *
$$

Select covariates

Critical thinking

$$
\begin{array}{lccc}
0.00(1.4 \%) & 0.01(3.2 \%) & 0.01(3.2 \%) & \\
0.07(24.0 \%) & * * * 0.06(28.4 \%) & * * * 0.06(19.5 \%) & * * \\
0.00(0.6 \%) & 0.00(-1.1 \%) & 0.06(18.5 \%) & * * *
\end{array}
$$

Need for cognition

Cognitively intense activities $0.00(0.6 \%)$

Cognitively intense engagement

with faculty

$0.02(7.9 \%) \quad \dagger \quad 0.00(1.4 \%) \quad 0.03(9.5 \%) \quad *$

Peer discussions about

diversity

$$
0.14(47.6 \%) \quad * * * 0.10(45.8 \%) \quad * * * 0.11(33.7 \%)
$$

\section{Coefficient effects}

Total

$$
-0.03(-9.1 \%) \quad-0.03(-15.3 \%) \quad-0.03(-8.7 \%)
$$

\section{Select covariates}

Critical thinking

$$
\begin{array}{lll}
1.03(355.4 \%) & 0.01(5.6 \%) & -0.68(-216.1 \%) \\
-0.18(-61.3 \%) & -0.08(-34.3 \%) & 0.68(215.1 \%) \dagger \\
0.01(3.5 \%) & 0.02(6.9 \%) & 0.01(3.0 \%)
\end{array}
$$

Need for cognition

Cognitively intense activities

Cognitively intense engagement

with faculty $0.00(1.0 \%)$ $-0.01(-3.3 \%)$ $-0.01(-3.6 \%)$

Peer discussions about diversity $0.00(-1.3 \%)$ $0.00(0.9 \%)$ $0.01(3.8 \%)$

Note: All covariates in the regression equation are included but results for other covariates are suppressed. Professional majors are the omitted category. Value: Values diversity experiences in education. Orient: Orientation toward diversity. Reflect: Reflection of views. $\uparrow \mathrm{p}<.10$, * $\mathrm{p}<.05, * * \mathrm{p}<.01, * * * \mathrm{p}<.001$ (two-tailed). 
Table 3 shows results from the Blinder-Oaxaca decomposition. Outcome differences between liberal arts and professional majors are due to differences in student characteristics, and in particular, to differences in the exposure to cognitive and cultural sophistication. Given that there were few moderating effects of cognitive and cultural sophistication by fields of study, it is not surprising that most of the difference in outcome gaps lies in differences in the distribution of covariates rather than differences in coefficient effects. Differences in need for cognition between liberal arts majors and professional majors account for $20 \%-28 \%$ of the gap in diversity outcomes by fields of study. There is modest evidence in the differences in diversity outcomes between liberal arts and professional majors which are due to cognitively intense activities or to cognitively intense engagement with faculty. Generally, differences in the exposure to cognitively intense activities and cognitively intense engagement with faculty account for less than $10 \%$ of the diversity outcome gaps. The exception is differences in the exposure to cognitively intense activities by fields of study account for about $19 \%$ of the difference in reflection of views scores. A notable portion of gaps in diversity outcomes - between $34 \%$ and $48 \%$ - is due to liberal arts majors who are more likely than professional majors who engage in peer discussions about diversity.

\section{Supplemental Analyses}

In addition to the main analysis, two supplemental analyses were conducted. In the first supplemental analysis, the peculiar finding of a negative effect of pre-college need for cognition on diversity outcomes was further investigated (See Table 2). Multicollinearity between need for cognition at time 3 (hereafter "need for cognition") and pre-college need for cognition may drive the positive effect of need for cognition on diversity outcomes, since multicollinearity may lead to erratic estimates (Fox, 1991). Need for cognition was excluded to investigate whether multicollinearity between pre-college need for cognition and need for cognition account for the negative relation between pre-college need for cognition and diversity outcomes; after all, the correlation between pre-college need for cognition and need for cognition is 0.56 . Result shows that excluding need for cognition changes the estimated coefficient for pre-college need for cognition where, for the most part, the relation between pre-college need for cognition and diversity outcomes is no longer significant. Although this finding differs from the negative effect of pre-college need for cognition in the model, results for pre-college need for cognition do not yield the same positive results as need for cognition. To investigate further, all other cognitive and cultural sophistication measures, both pre-college and college measures, were excluded with the exception of pre-college need for cognition. Excluding all other cognitive and cultural sophistication measures does not account for the null effect of pre-college need for cognition on diversity outcomes.

Upon further investigation, the main explanation for the null effect of pre-college need for cognition on diversity outcomes is due to the inclusion of the pre-college diversity measures and pre-college need for cognition. This finding makes sense because a positive relation between pre-college need for cognition and pre-college diversity outcomes is expected as shown by the findings for students during college. Indeed, correlations between pre-college need for cognition and pre-college diversity are as similar in magnitude compared with correlations between need for cognition and diversity outcomes in college.

In the second supplemental analysis, the null finding between critical thinking and diversity 
outcomes was reconsidered. Three analyses were made to test the robustness of this finding. First, the SAT scores were excluded from the model due to the strong correlation between SAT and pre-college critical thinking (0.70); results do not change from this supplemental analysis. Second, critical thinking was included but SAT scores and pre-college critical thinking were excluded. Again, results between critical thinking and diversity outcomes are statistically insignificant. Third, all cognitive and cultural sophistication measures other than critical thinking were excluded. Some evidence of a relation between critical thinking and diversity outcomes (e.g., reflection of views) is observed, but the influence is modest and marginally significant.

\section{Conclusion and Discussion}

Social scientists generally consider college education the central mechanism that increases tolerance toward other social groups. Studies generally show a positive relation between education and tolerance whereby college-educated individuals are more likely to exhibit favorable social attitudes than individuals without a college degree (Heerwig \& McCabe, 2009; Moore \& Ovadia, 2006; Sniderman \& Piazza, 1993). College participation exposes students to diverse individuals and multiple viewpoints and they are better able to comprehend nuances of social and political issues than nonstudents (Bobo \& Licari, 1989; Sniderman \& Piazza, 1993).

The study sheds light for research that considers education as the linchpin for a socially tolerant society in three ways. First, more complex measures were used than in previous studies to capture cognitive and cultural sophistication, the main mechanism through which college education raises social tolerance. Second, a more methodologically rigorous analysis was conducted in this study compared with past studies in which pre-college diversity measures were included to examine the effect of cognitive and cultural sophistication on diversity outcomes. Third, it was examined whether the rise of professional education undermines the liberalizing effect of college. Social scientists typically assume that college education exerts a liberalizing effect on social tolerance, in general, and they underplay students' field of study as influencing the relation between education and social tolerance.

Some evidence was observed that cognitive and cultural sophistication increases diversity outcomes. In particular, increases in need for cognition and peer discussions about diversity increase students' diversity outcomes, in most cases, by over 0.25 standard deviations. Weaker effects were found for other cognitive and cultural sophistication measures. For example, the largest influence of cognitively intense activities and cognitively intense engagement with faculty is moderately strong ( 0.16 standard deviations or smaller); oftentimes, the effects are non-significant. Surprisingly, little evidence was found that critical thinking raises diversity outcomes. This finding is a major departure from prior research that found a positive relation between verbal ability - a measure of abstract conceptual thinking - and social tolerance (Bobo \& Licari, 1989).

There are several possible explanations why the results of critical thinking on diversity outcomes differ from previous research. Previous research measured verbal ability at time of survey, where respondents vary considerably in age. Therefore, prior studies capture a respondent's cumulative measure of ability. Instead, this study focused on cognitive gains that occur during college. Overall, a positive zero-order correlation between critical thinking and 
diversity outcomes was found; but this relation disappears once students' critical thinking level prior to college was accounted for.

It was further considered whether the rise of professional education threatens the development of cognitive and cultural sophistication. Professional education tends to emphasize more on practical and specialized knowledge and less on general knowledge and intellectual inquiry (Goyette \& Mullen, 2006; Seifert et al., 2008). Results of this study suggest that universities should provide an education that promotes various returns to a college degree. As nations continue to experience demographic shifts in its racial/ethnic composition, the state of racial/ethnic relations remains a priority. Moreover, continued improvements in social relations needs emphasis on the liberalizing influence of college participation on social relations.

Little support was found that professional education lowers the liberalizing effect of college. In other words, the influence of cognitive and cultural sophistication on diversity outcomes was similar across fields of study. Nevertheless, liberal arts majors tend to have more favorable diversity outcomes than professional majors. A large portion of these differences was due to liberal arts majors exhibiting higher degrees of need for cognition and peer discussions about diversity than professional majors. Therefore, in terms of the effects of cognitive and cultural sophistication on diversity outcomes, it was not the difference between liberal arts and professional majors that was important, but rather that the exposure students received in their field of study accounted for a large part of diversity outcomes.

Although a more nuance measure of cognitive and cultural sophistication was provided in this study, previous research is able to compare between college-educated individuals and those without a college education. A limitation of this study is there is no appropriate comparison group to test the main question whether colleges increase cognitive and cultural sophistication for college students than non-college students. Perhaps a college education's main function is to maintain students' critical thinking level that they developed during their adolescence. If individuals who did not experience college have a large drop in their critical thinking levels on diversity outcomes, then colleges serve an important role. Despite this limitation, this study was able to examine a substantively important question of whether the relation between cognitive and cultural sophistication and diversity outcomes is lower for professional majors than liberal arts majors. Future efforts in data collection, however, need to include non-college students in order to test more broadly the role of college education in society.

\section{Acknowledgement}

This research is supported by a grant from the Center of Inquiry in the Liberal Arts at Wabash College to the Center for Research on Undergraduate Education at the University of Iowa. The opinions expressed are those of the authors and do not represent views of the Center of Inquiry in the Liberal Arts or the Center for Research on Undergraduate Education.

\section{References}

An, B. P., \& Gamoran, A. (2009). Trends in school racial composition in the era of unitary status. In C. E. Smrekar \& E. B. Goldring (Eds.), From the courtroom to the classroom: The shifting landscape of school desegregation (pp. 19-47). Cambridge, MA: Harvard Education 
Press.

Arum, R., Roksa, J., \& Velez, M. (2008). Learning to reason and communicate in college: Initial report of findings from the CLA Longitudinal Study. Brooklyn, NY: Social Science Research Council.

Ayers, J. W., Hofstetter, C. R., Schnakenberg, K., \& Kolody, B. (2009). Is immigration a racial issue? Anglo attitudes on immigration policies in a border county. Social Science Quarterly, 90, 593-610. http://dx.doi.org/10.1111/j.1540-6237.2009.00633.x

Bobo, L., \& Kluegel, J. R. (1993). Opposition to race-targeting: Self-interest, stratification ideology, or racial attitudes? American Sociological Review, 58, 443-464. http://dx.doi.org/10.2307/2096070

Bobo, L., \& Licari, F. C. (1989). Education and political tolerance: Testing the effects of cognitive sophistication and target group affect. Public Opinion Quarterly, 53, 285-308. http://dx.doi.org/10.1086/269154

Brint, S., Riddle, M., Turk-Bicakci, L., \& Levy, C. S. (2005). From the liberal to the practical arts in American colleges and universities: Organizational analysis and curricular change. Journal of Higher Education, 76, 151-180. http://dx.doi.org/10.1353/jhe.2005.0011

Center of Inquiry at Wabash College. (2011). Wabash National Study 2006-2009. Retrieved from http://www.liberalarts.wabash.edu/

Chang, M. J., Denson, N., Saenz, V., \& Misa, K. (2006). The educational benefits of sustaining cross-racial interaction among undergraduates. Journal of Higher Education, 77, 430-455. http://dx.doi.org/10.1353/jhe.2006.0018

Fox, J. (1991). Regression diagnostics. Newbury Park, CA: Sage Publications.

Freeman, J. A., \& Hirsch, B. T. (2008). College majors and the knowledge content of jobs. Economics of Education Review, 517-535. http://dx.doi.org/10.1016/j.econedurev.2007.07.004

Gaasholt, Ø., \& Togeby, L. (1995). Interethnic tolerance, education, and political orientation: Evidence from Denmark. Political Behavior, 17, 265-285. http://dx.doi.org/10.1007/BF01498597

Geys, B., \& Heyndels, B. (2003). Influence of 'cognitive sophistication' on ballot layout effects. Acta Politica, 38, 295-311. http://dx.doi.org/10.1057/palgrave.ap.5500040

Goyette, K. A., \& Mullen, A. L. (2006). Who studies the arts and sciences? Social background and the choice and consequences of undergraduate field of study. Journal of Higher Education, 77, 497-538. http://dx.doi.org/10.1353/jhe.2006.0020

Grogger, J., \& Eide, E. (1995). Changes in college skills and the rise in the college wage premium. Journal of Human Resources, 30, 280-310. http://dx.doi.org/10.2307/146120

Guimond, S., \& Palmer, D. L. (1996). The political socialization of commerce and social science students: Epistemic authority and attitude change. Journal of Applied Social Psychology, 26, 1985-2013. http://dx.doi.org/10.1111/j.1559-1816.1996.tb01784.x

Gurin, P., Dey, E. L., Hurtado, S., \& Gurin, G. (2002). Diversity and higher education: Theory and impact on educational outcomes. Harvard Educational Review, 72, 330-366.

Hanushek, E. A., Kain, J. F., \& Rivkin, S. G. (2009). New evidence about Brown v. Board of 
Education: The complex effects of school racial composition on achievement. Journal of Labor Economics, 27, 349-383. http://dx.doi.org/10.1086/600386

Heerwig, J. A., \& McCabe, B. J. (2009). Education and social desirability bias: The case of a Black presidential candidate. Social Science Quarterly, 90, 674-686. http://dx.doi.org/10.1111/j.1540-6237.2009.00637.x

Jann, B. (2008). The Blinder-Oaxaca decomposition for linear regression models. Stata Journal, 8, 453-479.

Krosnick, J., A., \& Alwin, D. F. (1987). An evaluation of a cognitive theory of response-order effects in survey measurement. Public Opinion Quarterly, 51, 201-219. http://dx.doi.org/10.1086/269029

Moore, L. M., \& Ovadia, S. (2006). Accounting for spatial variation in tolerance: The effects of education and religion. Social Forces, 84, 2205-2222. http://dx.doi.org/10.1353/sof.2006.0101

National Center for Education Statistics. (2009). The condition of education 2009 (NCES 2009-081). Retrieved from U.S. Department of Education Website: http://nces.ed.gov/pubsearch/pubsinfo.asp?pubid=2009081

Nunn, C. Z., Crockett, H. J., \& Williams, J. A. (1978). Tolerance for nonconformity. San Francisco: Jossey-Bass Publishers.

Park, J. J. (2009). Taking race into account: Charting student attitudes towards affirmative action. Research in Higher Education, 50, 670-690. http://dx.doi.org/10.1007/s11162-009-9138-7

Pascarella, E. T., \& Colleagues. (2007). Methodological report for Wabash National Study of Liberal Arts Education. University of Iowa, Center for Research on Undergraduate Education. Iowa City.

Paternoster, R., Brame, R., Mazerolle, P., \& Piquero, A. (1998). Using the correct statistical test for the equality of regression coefficients. Criminology, 36, 859-866. http://dx.doi.org/10.1111/j.1745-9125.1998.tb01268.x

Robst, J. (2007). Education and job match: The relatedness of college major and work. $\begin{array}{llll}\text { Economics of Education } & \text { Review, 26, }\end{array}$ http://dx.doi.org/10.1016/j.econedurev.2006.08.003

Scheepers, P., Gijsberts, M., \& Coenders, M. (2002). Ethnic exclusionism in European countries. Public opposition to civil rights for legal migrants as a response to perceived ethnic threat. European Sociological Review, 18, 17-34. http://dx.doi.org/10.1093/esr/18.1.17

Schuman, H., Steeh, C., Bobo, L., \& Krysan, M. (1997). Racial attitudes in America: Trends and interpretations, revised edition. Cambridge, MA: Harvard University Press.

Seifert, T. A. (2007). Does majoring in a "pure" versus "applied" field affect knowledge economy competency development? A multilevel, multi-institutional test of Biglan. Paper presented at the annual meeting of the Association for the Study of Higher Education, Louisville.

Seifert, T. A., Goodman, K. M., Lindsay, N., Jorgensen, J. D., Wolniak, G. C., Pascarella, E. T., \& Blaich, C. (2008). The effects of liberal arts experiences on liberal arts outcomes. 


\section{Macrothink}

Research in Higher Education, 49, 107-125. http://dx.doi.org/10.1007/s11162-007-9070-7

Sidanius, J., Pratto, F., Martin, M., \& Stallworth, L. M. (1991). Consensual racism and career track: Some implications of social dominance theory. Political Psychology, 12, 691-721. http://dx.doi.org/10.2307/3791552

Sniderman, P. M., \& Piazza, T. (1993). The scar of race. Cambridge, MA: Harvard University Press.

Stouffer, S. A. (1955). Communism, conformity and civil liberties. New York: Wiley.

Taylor, S. H. (1998). The impact of college on the development of tolerance. Journal of Student Affairs Research and Practice, 35, 281-295. http://dx.doi.org/10.2202/1949-6605.1065

Treas, J. (2002). How cohorts, education, and ideology shaped a new sexual revolution on American attitudes toward nonmarital sex, 1972-1998. Sociological Perspectives, 45, 267-283. http://dx.doi.org/10.1525/sop.2002.45.3.267

von Hippel, P. T. (2007). Regression with missing Ys: An improved strategy for analyzing multiply imputed data. Sociological Methodology, 37, 83-117. http://dx.doi.org/10.1111/j.1467-9531.2007.00180.x

Whitt, E. J., Edison, M. I., Pascarella, E. T., Terenzini, P. T., \& Nora, A. (2001). Influences on student's openness to diversity and challenge in the second and third years of college. Journal of Higher Education, 72, 172-204. http://dx.doi.org/10.2307/2649321

Wilson, T. C. (1994). Trends in tolerance toward rightist and leftist groups, 1976-1988: Effects of attitude change and cohort succession. Public Opinion Quarterly, 58, 539-556. http://dx.doi.org/10.1086/269446

\section{Copyright Disclaimer}

Copyright reserved by the author(s).

This article is an open-access article distributed under the terms and conditions of the Creative Commons Attribution license (http://creativecommons.org/licenses/by/3.0/). 